\title{
Correlates of high serum C-reactive protein levels in a socioeconomically disadvantaged population
}

\author{
Xianglan Zhang ${ }^{\mathrm{a}}$, Xiao-Ou Shu ${ }^{\mathrm{a}, *}$, Lisa B. Signorello ${ }^{\mathrm{a}, \mathrm{b}}$, Margaret K. Hargreaves ${ }^{\mathrm{c}}$, Qiuyin Cai ${ }^{\mathrm{a}}$, \\ MacRae F. Linton ${ }^{\mathrm{d}}$, Sergio Fazio ${ }^{\mathrm{d}}$, Wei Zheng ${ }^{\mathrm{a}}$ and William J. Blot ${ }^{\mathrm{a}, \mathrm{b}}$ \\ ${ }^{a}$ Department of Medicine, Vanderbilt Epidemiology Center, Vanderbilt University Medical Center, Nashville, TN, \\ USA \\ ${ }^{\mathrm{b}}$ International Epidemiology Institute, Rockville, MD, USA \\ ${ }^{\mathrm{c}}$ Department of Internal Medicine, Meharry Medical College, Nashville, TN, USA \\ ${ }^{\mathrm{d}}$ Department of Medicine, Atherosclerosis Research Unit, Vanderbilt University School of Medicine, Nashville, TN, \\ USA
}

\begin{abstract}
Individuals from low socioeconomic backgrounds are disproportionately affected by the burden of cardiovascular disease (CVD), yet data regarding risk factors in this population are lacking, particularly regarding emerging biomarkers of CVD such as C-reactive protein (CRP). We measured high-sensitivity CRP and examined its association with demographic and lifestyle factors in a sample of 792 participants aged 40-79 years from the Southern Community Cohort Study, which has an over-representation of socioeconomically disadvantaged individuals (over $60 \%$ with a total annual household income $<\$ 15,000$ ). We found that within this population the prevalence of elevated CRP $(>3 \mathrm{mg} / \mathrm{L})$ varied significantly by sex, race, smoking status, and body mass index (BMI). The multivariable-adjusted prevalence odds ratios (ORs) (95\% CIs) for having elevated CRP were 1.6 (1.1-2.3) for women vs. men, 1.4 (0.9-2.0) for African Americans vs. whites, 2.3 (1.4-3.8) for African American women vs. white men, 1.8 (1.2-2.7) for current smokers vs. non-smokers, and $4.2(2.7-6.6)$ for obese (BMI $30.0-44.9 \mathrm{~kg} / \mathrm{m}^{2}$ ) vs. healthyweight (BMI 18.3-24.9 kg/m²) participants. Further stratified analyses revealed that the association between BMI and elevated CRP was stronger among African Americans than whites and women than men, with prevalence ORs (95\% CI) comparing obese vs. healthy-weight categories reaching 22.8 (7.1-73.8) for African American women. In conclusion, in this socioeconomically disadvantaged population, sex, race, smoking, and BMI were associated with elevated CRP. Moreover, inflammatory response to obesity differed by race and sex, which may contribute to CVD disparities.
\end{abstract}

Keywords: C-reactive protein, obesity, race, sex

\section{Introduction}

A recent report on the state of disparities in cardiovascular health in the United States indicates that African Americans, persons with low socioeconomic

\footnotetext{
*Corresponding author: X.-O. Shu, Vanderbilt Epidemiology Center, Institute of Medicine \& Public Health, Vanderbilt University Medical Center, 2525 West End Avenue, Suite 600, Nashville, TN 37203-1738 (XO Shu), USA. Tel.: +1 615936 0713; Fax: +1 615 936 8291; E-mail: xiao-ou.shu@vanderbilt.edu.
}

status (SES), and residents of the southeastern United States are among the population subgroups most significantly affected by the burden of cardiovascular disease (CVD) [1]. Despite facing substantial health disadvantages, these populations have been poorly represented in epidemiologic and clinical studies. Understanding their CVD risk factors, including biomarkers and their related determinants, is an important first step toward improving cardiovascular health in these vulnerable populations. 
There is compelling evidence that atherosclerosis is an inflammatory disease [2]. C-reactive protein (CRP), an indicator of low-grade systemic inflammation, has emerged as a novel risk marker for CVD [2]. It adds predictive value across all levels of low-density lipoprotein cholesterol (LDL-C), the Framingham Risk Score, and the metabolic syndrome [2]. The Centers for Disease Control and Prevention (CDC) and the American Heart Association (AHA) have issued clinical guidelines for the use of high-sensitivity (hs) CRP testing in risk prediction for CVD [3]. However, the majority of biomarker studies have been conducted in predominantly white and high SES populations; data on inflammatory biomarkers in racial/ethnic minorities or populations with low SES are sparse.

We examined hsCRP in relation to demographic and lifestyle factors and further evaluated possible interactions of race and sex with lifestyle factors in a stratified random sample of 792 participants from the Southern Community Cohort Study (SCCS), a unique cohort study largely drawn from an underserved, socioeconomically disadvantaged population.

\section{Methods}

The SCCS is an ongoing prospective cohort study designed to identify causes and preventive strategies for health disparities in the United States. Details of the study methods have been described elsewhere [4]. Briefly, the study was initiated in 2001 and in 2002 began recruiting participants from community health centers (CHCs) across the southeastern United States. Participants were enrolled by randomly approaching people entering the $\mathrm{CHCs}$ (patients, persons accompanying patients, etc.) and screening them for eligibility and interest in study participation. Eligible participants were 40 to 79 years of age and had not been under treatment for cancer within the past year. As of October 31, 2004, approximately 33,000 participants had been enrolled from $25 \mathrm{CHCs}$ and completed a comprehensive baseline interview; over $50 \%$ of them had provided a non-fasting blood sample. Participants who reported infection with HIV or hepatitis were not asked for biospecimens.

The baseline study interview was conducted in person by trained interviewers at $\mathrm{CHCs}$ to elicit information on demographics, anthropometry, diet, use of tobacco and alcohol, physical activity, medical history, medication use, and other characteristics. Blood samples were refrigerated immediately after collection, shipped on a daily basis to Vanderbilt University, and processed for long-term storage at $-86^{\circ} \mathrm{C}$. The study was approved by the Institutional Review Boards at Vanderbilt University and Meharry Medical College. Informed consent was obtained from all participants.

In 2005, a series of biomarker studies including hsCRP were carried out using biospecimens from a stratified random sample of 792 SCCS participants, which formed the basis for the present analysis. A $2 \times 2 \times 3 \times 3$ factorial design was used to draw the sample and ensured the sample was evenly balanced by race (African American/white), sex (male/female), smoking (never/former/current), and body mass index (BMI, $18.0-24.9,25.0-29.9,30.0-45.0 \mathrm{~kg} / \mathrm{m}^{2}$ ) so that differences in biomarkers between these groups could be detected with substantially enhanced statistical power. Such a design also facilitated the evaluation of interactions between these factors.

\subsection{High-sensitivity CRP assay}

High-sensitivity CRP measurements were performed on thawed samples using the $A C E^{\circledR}$ High Sensitivity C-Reactive Protein Reagent (ACI-22) on ACE ${ }^{\circledR}$ Clinical Chemistry System (Alfa Wassermann, Inc, West Caldwell, NJ). The minimum detectable concentration of CRP was $0.1 \mathrm{mg} / \mathrm{L}$. The coefficients of variation were 0.9 to $2.4 \%$ for intra-assay and 1.8 to $4.9 \%$ for inter-assay.

\subsection{Statistical analysis}

The present analysis included 792 SCCS participants with hsCRP data. Descriptive statistics were first calculated for the study population. According to the CDC/AHA guidelines, an hsCRP level greater than $3 \mathrm{mg} / \mathrm{L}$ was defined as high-risk. Logistic regression models were used to calculate odds ratios (ORs) for the prevalence of high-risk CRP associated with sociodemographic and lifestyle factors and to adjust for potential confounding variables. Two multivariable models were applied in the analyses. Multivariable model 1 included age (3 categories), sex (male/female), race (African American/white), education level (3 categories), annual household income (3 categories), at least weekly attendance at religious services (yes/no), cigarette smoking (never, former, or current), alcohol consumption over the past year (rarely/never, monthly, or weekly), dietary intake of fruits and vegetables (times/day, 3 categories), participating in moderatevigorous sports (minutes/day, 3 categories), and BMI 
(calculated as weight in kilograms divided by the square of height in meters, 3 categories). Multivariable model 2 included all variables listed above plus measured total cholesterol, LDL-C, and high density lipoprotein cholesterol (HDL-C) levels (continuous), self-reported history of hypertension, diabetes, coronary heart disease (defined as having had a heart attack or coronary artery bypass surgery), stroke or transient ischemic attack (TIA), cancer, arthritis, asthma, or chronic bronchitis or emphysema (yes/no), regular use of aspirin within the past year (yes/no), current use of statins (yes/no), and family history of premature coronary heart disease (yes/no, defined as having had a heart attack or coronary artery bypass surgery at age $<65$ for female first-degree relatives or $<56$ for male firstdegree relatives). We also evaluated potential interactions of race and sex with lifestyle factors and high-risk hsCRP using nested models and the likelihood ratio test (LRT). Statistical analyses were performed using SAS version 9.1 (SAS Institute, Cary, NC). All statistical tests were based on two-sided probability.

The authors had full access to the data and take responsibility for its integrity. All authors have read and agreed to the manuscript as written.

\section{Results}

Table 1 shows the characteristics of the study population. By design, participants were evenly distributed across race, sex, smoking status, and BMI groups. The mean age of the participants was 53 years. Overall, the levels of education and household income of the participants were low. Nearly one-third had completed less than 12 years of schooling and over $60 \%$ reported a total annual household income of less than $\$ 15,000$. The prevalence of major chronic diseases was high.

Table 2 presents the percentile distribution of hsCRP by age, sex, race, smoking status, and BMI category. Women, current smokers, and those who were overweight or obese had significantly higher median hsCRP levels and a significantly higher prevalence of elevated hsCRP ( $>3 \mathrm{mg} / \mathrm{L}$ ) compared with their respective counterparts $\left(\chi^{2} p\right.$-values all $\left.<0.05\right)$. Elevated hsCRP also appeared to be slightly more prevalent in participants age 50 years or older compared to those less than age 50 years and in African Americans compared to whites, but the differences were not statistically significant ( $\chi^{2} p$-value $=0.4$ for each comparison).

Table 3 summarizes the ORs and 95\% confidence intervals (CIs) of high-risk CRP according to socio- demographic and lifestyle factors. After adjustment for potential confounders, sex, race, smoking status, and BMI were all associated with high-risk CRP. The fully adjusted ORs (95\% CIs) for having hsCRP $>3 \mathrm{mg} / \mathrm{L}$ were 1.6 (1.1-2.3) for women (not on hormone therapy) vs. men, 1.4 (0.9-2.0) for African Americans vs. whites, 1.8 (1.2-2.7) for current smokers vs. nonsmokers, and 4.2 (2.7-6.6) for obese vs. healthy-weight participants. Additionally excluding premenopausal women $(n=117)$ from the analysis did not appreciably alter the gender-based results. When race and sex were evaluated jointly, African American women had 2.3fold higher odds (95\% CI, 1.4-3.8) of elevated hsCRP compared with white men. SES, alcohol consumption, exercise, and other lifestyle factors showed some significant associations with high-risk CRP in univariate analyses but not in multivariable analyses. No association was found for age in either of the analyses.

We conducted further stratified analyses and found significant interactions between race, sex and BMI and high-risk CRP (Table 4). The fully adjusted ORs (95\% CIs) of high-risk CRP comparing obese (BMI $\geqslant 30 \mathrm{~kg} / \mathrm{m}^{2}$ ) vs. healthy-weight (BMI $<25 \mathrm{~kg} / \mathrm{m}^{2}$ ) categories were 5.5 (2.8-11.0) for African Americans vs. 3.0 (1.5-5.7) for whites, and $7.6(4.0-14.7)$ for women vs. 2.5 (1.3-5.0) for men (LRT $p$-values for multiplicative interaction both $<0.05)$. The strongest association was observed among African American women, with an OR for obese women vs. healthy-weight women of 22.8 (7.1-73.8). The percentage of obese African American women with an elevated hsCRP was $72.7 \%$, whereas only $18.2 \%$ of African American women with BMI $<25 \mathrm{~kg} / \mathrm{m}^{2}$ had hsCRP levels exceeding $3 \mathrm{mg} / \mathrm{L}$. There was no evidence for any interaction of race or sex with other lifestyle factors.

hsCRP levels were significantly but weakly correlated with levels of total cholesterol (Spearman correlation coefficient, $r=0.09)$, LDL-C $(r=0.11)$, and HDL-C $(r=-0.17)$ (p-values all $<0.05)$. The percentages of elevated hsCRP were $41 \%$ for participants with high total cholesterol $(\geqslant 200 \mathrm{mg} / \mathrm{dL})$ vs. $34 \%$ for those with lower total cholesterol ( $\mathrm{p}$-value $=0.06), 43 \%$ for those with high LDL-C ( $\geqslant 130 \mathrm{mg} / \mathrm{dL})$ vs. $34 \%$ for those with lower LDL-C (p-value $=0.01$ ), and $48 \%$ for those with low HDL-C $(<40 \mathrm{mg} / \mathrm{dL}$ for men and $<50 \mathrm{mg} / \mathrm{dL}$ for women) vs. $32 \%$ for those with higher HDL-C (p-value $<0.01$ ). Elevated hsCRP was also associated with the prevalence of history of hypertension $(\mathrm{OR}=2.3 ; 95 \% \mathrm{CI}, 1.7-3.0)$, coronary heart disease $(\mathrm{OR}=1.9 ; 95 \% \mathrm{CI}, 1.1-3.2)$, arthritis $(\mathrm{OR}=1.7 ; 95 \%$ CI, 1.2-2.3), and chronic bronchitis/emphysema (OR 
Table 1

Characteristics of the study population

\begin{tabular}{|c|c|}
\hline Variable & \\
\hline Age $(y)$, mean (SD) & $53.0(9.4)$ \\
\hline \multicolumn{2}{|l|}{ Race and sex, n (\%) } \\
\hline White men & $198(25.0)$ \\
\hline African American men & $198(25.0)$ \\
\hline White women & $198(25.0)$ \\
\hline African American women & $198(25.0)$ \\
\hline \multicolumn{2}{|l|}{ Education, $\mathrm{n}(\%)$} \\
\hline Less than high school & $244(30.8)$ \\
\hline High school or GED* & $327(41.3)$ \\
\hline More than high school & $221(27.9)$ \\
\hline \multicolumn{2}{|l|}{ Annual household income (\$), n (\%) } \\
\hline$<15,000$ & $480(60.6)$ \\
\hline $15,000-24,999$ & $167(21.1)$ \\
\hline$\geqslant 25,000$ & $139(17.6)$ \\
\hline Unknown & $6(0.8)$ \\
\hline At least weekly attendance at religious services, n (\%) & $362(45.8)$ \\
\hline \multicolumn{2}{|l|}{ Cigarette smoking, $\mathrm{n}(\%)$} \\
\hline Never & $264(33.3)$ \\
\hline Former & $264(33.3)$ \\
\hline Current & $264(33.3)$ \\
\hline \multicolumn{2}{|l|}{ Alcohol consumption, $\mathrm{n}(\%)$} \\
\hline Rarely or never & $496(62.7)$ \\
\hline Monthly & $76(9.6)$ \\
\hline Weekly & $219(27.7)$ \\
\hline Unknown & $1(0.0)$ \\
\hline \multicolumn{2}{|l|}{ Fruit and vegetable intake (times/d), n (\%) } \\
\hline $0-1$ & $153(19.3)$ \\
\hline $2-4$ & $505(63.8)$ \\
\hline At least 5 & $134(16.9)$ \\
\hline Exercise (min/d), median (IQR ${ }^{\dagger}$ ) & $0.0(0.0-17.1)$ \\
\hline \multicolumn{2}{|l|}{ Body mass index $\left(\mathrm{kg} / \mathrm{m}^{2}\right), \mathrm{n}(\%)$} \\
\hline $18.3-24.9$ & $264(33.3)$ \\
\hline $25.0-29.9$ & $264(33.3)$ \\
\hline $30.0-44.9$ & $264(33.3)$ \\
\hline \multicolumn{2}{|l|}{ Medications, n (\%) } \\
\hline Current HRT $^{\ddagger}$ use in women & $71(17.9)$ \\
\hline Regular aspirin use within the past year & $123(15.6)$ \\
\hline Current statin use & $96(12.1)$ \\
\hline \multicolumn{2}{|l|}{ Medical conditions, $\mathrm{n}(\%)$} \\
\hline Hypertension & $411(51.9)$ \\
\hline Diabetes & $140(17.7)$ \\
\hline Coronary heart disease (previous heart attack or coronary artery bypass surgery) & $56(7.0)$ \\
\hline Stroke or transient ischemic attack & $48(6.1)$ \\
\hline Cancer & $66(8.3)$ \\
\hline Arthritis & $268(33.8)$ \\
\hline Asthma & $120(15.2)$ \\
\hline Chronic bronchitis or emphysema & $98(12.4)$ \\
\hline Total cholesterol (mg/dL), mean (SD) & $209.1(44.9)$ \\
\hline LDL-C (mg/dL), mean (SD) & $125.3(38.1)$ \\
\hline $\mathrm{HDL}{ }^{\|}(\mathrm{mg} / \mathrm{dL})$, mean $(\mathrm{SD})$ & $51.9(15.1)$ \\
\hline Family history of premature heart attack or coronary artery bypass surgery & $158(20.0)$ \\
\hline
\end{tabular}

${ }^{*}$ GED, general equivalency diploma; ${ }^{\dagger} \mathrm{IQR}$, interquartile range; ${ }^{\ddagger} \mathrm{HRT}$, hormone replacement therapy;

LDL-C, low-density lipoprotein cholesterol; " HDL-C, high-density lipoprotein cholesterol.

$=2.0 ; 95 \% \mathrm{CI}, 1.3-3.0)$ in univariate analyses, but only the association with hypertension remained statistically significant in multivariable analyses, with an adjusted OR of 1.9 (95\% CI, 1.3-2.8) (data not shown).
In addition, stratified analyses revealed that, similar to the finding for BMI, the association between elevated hsCRP and hypertension also differed by race and sex, with adjusted ORs (95\% CIs) of $1.3(0.5-3.0), 2.9$ (1.2- 
Table 2

Distribution of hsCRP values by age, sex, race, smoking status, and BMI category

\begin{tabular}{|c|c|c|c|c|c|c|c|c|c|}
\hline & \multicolumn{8}{|c|}{ Percentile } & \multirow[t]{2}{*}{$\mathrm{CRP}>3 \mathrm{mg} / \mathrm{L}, \%$} \\
\hline & $\mathrm{n}$ & 5 th & 10th & 25 th & 50 th & 75th & 90th & 95th & \\
\hline \multicolumn{10}{|l|}{ Age (y) } \\
\hline $40-49$ & 362 & 0.1 & 0.2 & 0.7 & 2.0 & 4.7 & 9.5 & 16.2 & 35.9 \\
\hline $50-59$ & 253 & 0.2 & 0.3 & 0.8 & 2.2 & 4.7 & 11.6 & 22.5 & 38.7 \\
\hline 60-79 & 177 & 0.2 & 0.5 & 1.0 & 2.4 & 4.6 & 11.8 & 18.2 & 39.0 \\
\hline \multicolumn{10}{|l|}{ Sex } \\
\hline Male & 396 & 0.2 & 0.2 & 0.7 & 1.7 & 4.0 & 9.5 & 17.6 & 32.3 \\
\hline Female & 396 & 0.2 & 0.4 & 1.0 & 2.6 & 5.8 & 12.0 & 17.4 & 42.7 \\
\hline Female not taking HRT & 325 & 0.2 & 0.4 & 1.0 & 2.4 & 5.6 & 11.8 & 18.0 & 41.9 \\
\hline \multicolumn{10}{|l|}{ Race } \\
\hline White & 396 & 0.2 & 0.3 & 0.9 & 2.1 & 4.4 & 9.5 & 15.0 & 35.9 \\
\hline African American & 396 & 0.1 & 0.2 & 0.7 & 2.2 & 5.1 & 12.0 & 21.5 & 39.1 \\
\hline \multicolumn{10}{|l|}{ Race and sex } \\
\hline White men & 198 & 0.2 & 0.3 & 0.9 & 1.9 & 3.7 & 9.4 & 16.8 & 32.8 \\
\hline African American men & 198 & 0.1 & 0.2 & 0.6 & 1.6 & 4.4 & 9.8 & 23.0 & 31.8 \\
\hline White women & 198 & 0.2 & 0.3 & 0.9 & 2.3 & 5.5 & 10.0 & 13.6 & 38.9 \\
\hline African American women & 198 & 0.2 & 0.4 & 1.0 & 2.9 & 6.2 & 14.0 & 21.5 & 46.5 \\
\hline \multicolumn{10}{|l|}{ Cigarette smoking } \\
\hline Never & 264 & 0.1 & 0.2 & 0.7 & 1.8 & 3.6 & 7.2 & 13.6 & 31.8 \\
\hline Former & 264 & 0.2 & 0.3 & 0.8 & 2.0 & 4.7 & 10.0 & 17.6 & 36.4 \\
\hline Current & 264 & 0.2 & 0.3 & 1.1 & 2.6 & 6.3 & 13.4 & 23.5 & 44.3 \\
\hline \multicolumn{10}{|l|}{ Body mass index $\left(\mathrm{kg} / \mathrm{m}^{2}\right)$} \\
\hline $18.3-24.9$ & 264 & 0.1 & 0.2 & 0.4 & 1.2 & 2.7 & 6.5 & 9.8 & 19.7 \\
\hline $25.0-29.9$ & 264 & 0.2 & 0.4 & 0.9 & 2.2 & 4.5 & 12.8 & 20.5 & 36.0 \\
\hline $30.0-44.9$ & 264 & 0.3 & 0.7 & 1.6 & 3.5 & 6.7 & 15.0 & 22.5 & 56.8 \\
\hline
\end{tabular}

7.4), 2.0 (0.9-4.4), and 5.0 (1.8-14.5), respectively, for white men, African American men, white women, and African American women. No significant association was found between elevated hsCRP and current use of statins or use of aspirin within the past year.

\section{Discussion}

In this cross-sectional analysis of a stratified random sample of SCCS participants, female sex, African American race, smoking, and high BMI were significantly associated with elevated hsCRP after accounting for a wide range of potential confounding variables, including SES, physical activity, medical conditions related to inflammation and medication use. Of particular interest, however, was the finding that the strength of the association between BMI and elevated hsCRP differed substantially by both race and sex. BMI was more strongly associated with high-risk CRP in African Americans and women than in their white and male counterparts. The association between BMI and hsCRP was strongest among African American women.

Several previous studies have examined the relation between socio-demographic factors and CRP levels. As in our study, levels of CRP were found to increase minimally with age in the Women's Health Study [5].
In contrast, data from the National Health and Nutrition Examination Survey showed a significant increase in CRP levels with older age [6]. Studies conducted in the US, in general, have indicated that women have higher CRP levels than men [6-8]. For example, the Multiethnic Study of Atherosclerosis found higher CRP levels in women than men across four ethnic groups, and the gender differences persisted after accounting for potential confounding variables [7]. However, the opposite pattern was reported in a study from Japan [9], and fewer gender differences were reported in studies of European populations [10]. Although not entirely consistent, CRP levels have generally been found to be higher in African Americans than in whites [8,11]. A recent review of population-based studies addressing SES and inflammatory markers concluded that SES was inversely and independently associated with CRP levels [12].

Investigations of lifestyle correlates of CRP have shown a consistent positive relation between cigarette smoking and CRP levels $[13,14]$. While several studies have reported an independent inverse association between physical activity and CRP levels [15-17], others have found no association after adjustment for BMI and other confounders [18,19]. A limited number of studies have related higher intakes of fruits and vegetables and moderate alcohol consumption to lower CRP levels [20, 
Table 3

Odds ratios for high-risk CRP according to sociodemographic and lifestyle factors

\begin{tabular}{|c|c|c|c|}
\hline Variable & Crude OR & Multivariable $\mathrm{OR}^{*}$ & Multivariable $\mathrm{OR}^{\dagger}$ \\
\hline \multicolumn{4}{|l|}{ Age (y) } \\
\hline $40-49$ & 1.0 & 1.0 & 1.0 \\
\hline $50-59$ & $1.1(0.8-1.6)$ & $1.2(0.8-1.7)$ & $0.9(0.6-1.4)$ \\
\hline $60-79$ & $1.1(0.8-1.7)$ & $1.2(0.8-1.9)$ & $0.9(0.6-1.5)$ \\
\hline \multicolumn{4}{|l|}{ Sex } \\
\hline Male & 1.0 & 1.0 & 1.0 \\
\hline Female & $1.6(1.2-2.1)$ & $1.5(1.1-2.1)$ & $1.7(1.2-2.4)$ \\
\hline Female not taking HRT & $1.5(1.1-2.0)$ & $1.4(1.0-2.0)$ & $1.6(1.1-2.3)$ \\
\hline \multicolumn{4}{|l|}{ Race } \\
\hline White & 1.0 & 1.0 & 1.0 \\
\hline African American & $1.2(0.9-1.5)$ & $1.3(0.9-1.8)$ & $1.4(0.9-2.0)$ \\
\hline \multicolumn{4}{|l|}{ Race and sex } \\
\hline White men & 1.0 & 1.0 & 1.0 \\
\hline African American men & $1.0(0.6-1.5)$ & $1.0(0.6-1.7)$ & $1.1(0.7-1.8)$ \\
\hline White women & $1.3(0.9-2.0)$ & $1.2(0.8-1.9)$ & $1.3(0.8-2.2)$ \\
\hline African American women & $1.8(1.2-2.7)$ & $1.9(1.2-3.0)$ & $2.3(1.4-3.8)$ \\
\hline \multicolumn{4}{|l|}{ Education } \\
\hline Less than high school & 1.0 & 1.0 & 1.0 \\
\hline High school or GED & $1.0(0.7-1.4)$ & $1.0(0.7-1.5)$ & $1.0(0.7-1.5)$ \\
\hline More than high school & $0.7(0.5-1.1)$ & $0.9(0.5-1.3)$ & $0.8(0.5-1.3)$ \\
\hline \multicolumn{4}{|l|}{ Annual household income, \$ } \\
\hline$<15,000$ & 1.0 & 1.0 & 1.0 \\
\hline $15,000-24,999$ & $0.9(0.6-1.3)$ & $0.9(0.6-1.3)$ & $0.8(0.5-1.2)$ \\
\hline$\geqslant 25,000$ & $0.7(0.5-1.1)$ & $0.9(0.6-1.4)$ & $0.9(0.6-1.5)$ \\
\hline \multicolumn{4}{|l|}{ Attendance at religious services } \\
\hline Less than once per week & 1.0 & 1.0 & 1.0 \\
\hline At least once per week & $0.8(0.6-1.0)$ & $0.7(0.6-1.4)$ & $0.8(0.5-1.1)$ \\
\hline \multicolumn{4}{|l|}{ Cigarette smoking } \\
\hline Never & 1.0 & 1.0 & 1.0 \\
\hline Former & $1.2(0.9-1.8)$ & $1.2(0.8-1.8)$ & $1.2(0.8-1.8)$ \\
\hline Current & $1.7(1.2-2.4)$ & $1.9(1.2-2.8)$ & $1.8(1.2-2.7)$ \\
\hline \multicolumn{4}{|l|}{ Alcohol consumption } \\
\hline Rarely or never & 1.0 & 1.0 & 1.0 \\
\hline Monthly & $1.1(0.7-1.8)$ & $1.4(0.8-2.4)$ & $1.4(0.8-2.4)$ \\
\hline Weekly & $0.6(0.4-0.8)$ & $0.7(0.5-1.0)$ & $0.7(0.5-1.1)$ \\
\hline \multicolumn{4}{|c|}{ Fruit and vegetable intake, times/d } \\
\hline $0-1$ & 1.0 & 1.0 & 1.0 \\
\hline $2-4$ & $0.9(0.6-1.3)$ & $1.0(0.6-1.5)$ & $1.1(0.7-1.7)$ \\
\hline At least 5 & $0.8(0.5-1.2)$ & $0.9(0.5-1.5)$ & $0.9(0.5-1.6)$ \\
\hline \multicolumn{4}{|l|}{ Exercise, $\mathrm{min} / \mathrm{d}$} \\
\hline 0 & 1.0 & 1.0 & 1.0 \\
\hline$\leqslant 30$ & $1.0(0.7-1.4)$ & $1.3(0.8-1.9)$ & $1.4(0.9-2.1)$ \\
\hline$>30$ & $0.5(0.3-0.7)$ & $0.8(0.5-1.3)$ & $0.9(0.5-1.5)$ \\
\hline \multicolumn{4}{|l|}{ Body mass index, $\mathrm{kg} / \mathrm{m}^{2}$} \\
\hline $18.3-24.9$ & 1.0 & 1.0 & 1.0 \\
\hline $25.0-29.9$ & $2.3(1.5-3.4)$ & $2.3(1.5-3.4)$ & $1.9(1.2-2.9)$ \\
\hline $30.0-44.9$ & $5.4(3.6-7.9)$ & $5.4(3.6-8.1)$ & $4.2(2.7-6.6)$ \\
\hline
\end{tabular}

* Multivariable model 1: Included all variables listed in the table.

${ }^{\dagger}$ Multivariable model 2: Included all variables listed in the table plus total cholesterol, HDL-C, and LDL-C, history of hypertension, diabetes, coronary heart disease, stroke or transient ischemic attack, cancer, arthritis, asthma, or chronic bronchitis/emphysema, use of aspirin within the past year, current use of statins, and family history of premature coronary heart disease.

21]. Notably, BMI was among the most consistently identified correlates of CRP [15,19,22].

Thus, the results of our study, which was specifically powered to detect differences in CRP by race, sex, smoking and BMI, are generally in agreement with the results of previous studies, but extend previous findings by demonstrating striking race and sex differences in the strength of the association between BMI and CRP. The particularly strong association observed among African American women may have significant impli- 
Table 4

Odds ratios for high-risk CRP according to body mass index (BMI), stratified by race and sex

\begin{tabular}{|c|c|c|c|c|c|c|}
\hline & & $\mathrm{N}$ & Median BMI & Crude OR & Multivariable $\mathrm{OR}^{*}$ & Multivariable $\mathrm{OR}^{\dagger}$ \\
\hline \multicolumn{7}{|l|}{ Whites } \\
\hline \multirow[t]{3}{*}{ BMI } & $18.3-24.9$ & 132 & 22.8 & 1.0 & 1.0 & 1.0 \\
\hline & $25.0-29.9$ & 132 & 27.4 & $1.5(0.9-2.6)$ & $1.4(0.8-2.6)$ & $1.2(0.6-2.2)$ \\
\hline & $30.0-44.9$ & 132 & 34.5 & $3.6(2.1-6.0)$ & $3.7(2.0-6.6)$ & $3.0(1.5-5.7)$ \\
\hline \multicolumn{7}{|c|}{ African Americans } \\
\hline \multirow[t]{3}{*}{ BMI } & $18.3-24.9$ & 132 & 22.8 & 1.0 & 1.0 & 1.0 \\
\hline & $25.0-29.9$ & 132 & 27.5 & $3.5(2.0-6.3)$ & $3.5(1.9-6.4)$ & $2.9(1.5-5.5)$ \\
\hline & $30.0-44.9$ & 132 & 34.3 & $8.4(4.7-15.0)$ & $8.3(4.5-15.6)$ & $5.5(2.8-11.0)$ \\
\hline \multicolumn{7}{|l|}{ Men } \\
\hline \multirow[t]{3}{*}{ BMI } & $18.3-24.9$ & 132 & 22.9 & 1.0 & 1.0 & 1.0 \\
\hline & $25.0-29.9$ & 132 & 27.1 & $1.4(0.8-2.5)$ & $1.5(0.8-2.7)$ & $1.1(0.6-2.2)$ \\
\hline & $30.0-44.9$ & 132 & 34.2 & $3.5(2.0-6.0)$ & $3.4(1.9-6.0)$ & $2.5(1.3-5.0)$ \\
\hline \multicolumn{7}{|l|}{ Women } \\
\hline \multirow[t]{3}{*}{ BMI } & $18.3-24.9$ & 132 & 22.3 & 1.0 & 1.0 & 1.0 \\
\hline & $25.0-29.9$ & 132 & 27.7 & $3.6(2.1-6.4)$ & $3.6(2.0-6.6)$ & $3.2(1.7-5.9)$ \\
\hline & $30.0-44.9$ & 132 & 34.7 & $8.4(4.8-14.9)$ & $8.9(4.8-16.4)$ & $7.6(4.0-14.7)$ \\
\hline \multicolumn{7}{|c|}{ White men } \\
\hline \multirow[t]{3}{*}{ BMI } & $18.3-24.9$ & 66 & 23.0 & 1.0 & 1.0 & 1.0 \\
\hline & $25.0-29.9$ & 66 & 27.3 & $0.7(0.3-1.6)$ & $0.7(0.3-1.7)$ & $0.5(0.2-1.4)$ \\
\hline & $30.0-44.9$ & 66 & 34.7 & $2.2(1.1-4.5)$ & $2.2(0.9-5.1)$ & $1.9(0.7-5.5)$ \\
\hline \multicolumn{7}{|c|}{ African American men } \\
\hline \multirow[t]{3}{*}{ BMI } & $18.3-24.9$ & 66 & 22.8 & 1.0 & 1.0 & 1.0 \\
\hline & $25.0-29.9$ & 66 & 26.9 & $3.0(1.2-7.1)$ & $3.3(1.3-8.5)$ & $2.4(0.8-7.5)$ \\
\hline & $30.0-44.9$ & 66 & 33.9 & $6.3(2.7-14.9)$ & $5.9(2.4-14.8)$ & $2.8(0.9-8.8)$ \\
\hline \multicolumn{7}{|c|}{ White women } \\
\hline \multirow[t]{3}{*}{ BMI } & $18.3-24.9$ & 66 & 22.4 & 1.0 & 1.0 & 1.0 \\
\hline & $25.0-29.9$ & 66 & 27.4 & $3.1(1.4-6.9)$ & $2.9(1.2-7.3)$ & $2.3(0.9-6.4)$ \\
\hline & $30.0-44.9$ & 66 & 34.4 & $6.1(2.8-13.5)$ & $5.7(2.3-14.0)$ & $4.6(1.7-12.7)$ \\
\hline \multicolumn{7}{|c|}{ African American women } \\
\hline \multirow[t]{3}{*}{ BMI } & $18.3-24.9$ & 66 & 22.3 & 1.0 & 1.0 & 1.0 \\
\hline & $25.0-29.9$ & 66 & 27.9 & $4.2(1.9-9.3)$ & $4.8(2.0-11.6)$ & $6.2(2.2-17.4)$ \\
\hline & $30.0-44.9$ & 66 & 34.9 & $12.0(5.2-27.4)$ & $17.2(6.6-44.6)$ & $22.8(7.1-73.8)$ \\
\hline
\end{tabular}

* Multivariable model 1: Included all variables listed in Table 3 except for the variables used for stratification;

${ }^{\dagger}$ Multivariable model 2: Additionally adjusted for total cholesterol, HDL-C, and LDL-C, history of hypertension, diabetes, coronary heart disease, stroke or transient ischemic attack, cancer, arthritis, asthma, or chronic bronchitis/emphysema, use of aspirin within the past year, current use of statins, and family history of premature coronary heart disease.

cations given the high prevalence rate of obesity in this group $[4,23]$ and the crucial role of inflammation in the development of CVD [2].

Adipose tissue has been recognized as an important source of inflammatory cytokines [24]. It contributes approximately $30 \%$ of circulating interleukin-6, a major cytokine that stimulates the hepatic production of CRP [25]. Recent evidence suggests that the adipocytespecific cytokines leptin and adiponectin may also play a role in modulating CRP levels [26-28]. With increasing adiposity, production of interleukin- 6 and leptin increase, whereas adiponectin production decreases, leading to a state of low-grade systemic inflammation [24-28]. In addition to the level of adiposity, the distribution of adipose tissue also relates to the secretion of these adipocytokines [29]. Body composition and fat patterning have been shown to differ by sex and race [29-31]. For a given BMI, women have greater amounts of total body fat than men, and African Americans have less visceral but more muscular adipose tissue compared with whites in general [29-31]. Together, these observations suggest that variations in both body composition and fat patterning among different sex and race groups could underlie the differential associations between BMI and CRP by sex and race seen in our study. Further investigations with accurate measures of total body fat and different fat deposit patterns are clearly needed to clarify this issue.

It is interesting to note that, in addition to CRP, significant differences by sex and race also exist in levels of leptin and adiponectin [27,32,33]. For example, a recent report from the Dallas Heart Study showed that for a given fat "burden" as measured by dual energy Xray scan, women had higher leptin levels and a greater increase in CRP per unit increase in leptin compared with men [27]. In a multiethnic cohort of obese chil- 
dren and adolescents, a lower adiponectin level and a stronger inverse association between adiponectin and CRP were observed among obese African Americans and Hispanics compared with whites [33]. Such data, although limited, provide support to the notion that fat mass alone may be insufficient to explain the race and sex differences.

A unique feature of our study is that all participants were recruited from $\mathrm{CHCs}$ which provide basic health services primarily to low income individuals. The relative homogeneity of the participants with respect to SES and educational backgrounds reduces confounding by SES-associated tangible and intangible factors (such as social and economic stress) in assessing health risks and risk factors; this is particularly important in making comparisons across race and sex. On the other hand, the homogenous SES background of our study participants limited our ability to evaluate the relationships of SES and psychosocial stress with CRP. Another strength of the study is the use of an in-person interview, which is preferable to phone or self-administered surveys, especially for populations with low SES and educational levels.

Our study is limited mainly by its cross-sectional design, a relatively small sample size, a lack of information on body fat distribution, and possible residual confounding from crudely measured or unmeasured covariates. Measurement errors in the assessment of diet and physical activity may have contributed to the lack of associations between these lifestyle variables and CRP. All of these methodological limitations should be considered when interpreting the results. Nevertheless, our study is the largest investigation to date of the correlates of elevated CRP in a socioeconomically disadvantaged population. Our finding of a positive relationship between BMI and CRP that varied substantially among different race and sex groups suggests that differential inflammatory response to obesity by race and sex may contribute to the disparities in morbidity and mortality from CVD and other chronic diseases. Obese African American women are particularly prone to activating a state of chronic low-level inflammation that may further increase their CVD risk. Future investigation of this hypothesis is warranted.

\section{Acknowledgements}

Funding Sources: United States Public Health Service grant number R01 CA92447 from the National Institutes of Health. Dr. Zhang was supported by an NIH- sponsored Building Interdisciplinary Research Careers in Women's Health (BIRCWH) Program at Vanderbilt University (2K12HD043483-06).

\section{References}

[1] G.A. Mensah, A.H. Mokdad, E.S. Ford, K.J. Greenlund and J.B. Croft, State of disparities in cardiovascular health in the United States, Circulation 111 (2005), 1233-1241.

[2] P. Libby and P.M. Ridker, Inflammation and atherothrombosis from population biology and bench research to clinical practice, J Am Coll Cardiol 48 (2006), A33-A46.

[3] T.A. Pearson, G.A. Mensah, R.W. Alexander, J.L. Anderson, R.O. Cannon 3rd, M. Criqui, Y.Y. Fadl, S.P. Fortmann, Y. Hong, G.L. Myers, N. Rifai, S.C. Smith Jr, K. Taubert, R.P. Tracy and F. Vinicor, Centers for Disease Control and Prevention; American Heart Association. Markers of inflammation and cardiovascular disease: application to clinical and public health practice: A statement for healthcare professionals from the Centers for Disease Control and Prevention and the American Heart Association, Circulation 107 (2003), 499-511.

[4] L.B. Signorello, M.K. Hargreaves, M.D. Steinwandel, W. Zheng, Q. Cai, D.G. Schlundt, M.S. Buchowski, C.W. Arnold, J.K. McLaughlin and W.J. Blot, Southern community cohort study: establishing a cohort to investigate health disparities, $J$ Natl Med Assoc 97 (2005), 972-979.

[5] N. Rifai and P.M. Ridker, Population distributions of Creactive protein in apparently healthy men and women in the United States: implication for clinical interpretation, Clin Chem 49 (2003), 666-669.

[6] S. Woloshin and L.M. Schwartz, Distribution of C-reactive protein values in the United States, N Engl J Med 352 (2005), 1611-1613.

[7] S.G. Lakoski, M. Cushman, M. Criqui, T. Rundek, R.S. Blumenthal, R.B. D'Agostino Jr and D.M. Herrington, Gender and C-reactive protein: data from the Multiethnic Study of Atherosclerosis (MESA) cohort, Am Heart J 152 (2006), 593598.

[8] A. Khera, D.K. McGuire, S.A. Murphy, H.G. Stanek, S.R. Das, W. Vongpatanasin, F.H. Wians Jr, S.M. Grundy and J.A. de Lemos, Race and gender differences in C-reactive protein levels, J Am Coll Cardiol 46 (2005), 464-469.

[9] S. Yamada, T. Gotoh, Y. Nakashima, K. Kayaba, S. Ishikawa, N. Nago, Y. Nakamura, Y. Itoh and E. Kajii, Distribution of serum C-reactive protein and its association with atherosclerotic risk factors in a Japanese population: Jichi Medical School Cohort Study, Am J Epidemiol 153(12) (2001), 11831190.

[10] A. Imhof, M. Fröhlich, H. Loewel, N. Helbecque, M. Woodward, P. Amouyel, G.D. Lowe and W. Koenig, Distributions of C-reactive protein measured by high-sensitivity assays in apparently healthy men and women from different populations in Europe, Clin Chem 49(4) (2003), 669-672.

[11] M.A. Albert, R.J. Glynn, J. Buring and P.M. Ridker, C-reactive protein levels among women of various ethnic groups living in the United States (from the Women's Health Study), Am J Cardiol 93 (2004), 1238-1242.

[12] A. Nazmi and C.G. Victora, Socioeconomic and racial/ethnic differentials of C-reactive protein levels: a systematic review of population-based studies, BMC Public Health 7 (2007), 212. 
[13] S.G. Wannamethee, G.D. Lowe, A.G. Shaper, A. Rumley, L. Lennon and P.H. Whincup, Associations between cigarette smoking, pipe/cigar smoking, and smoking cessation, and haemostatic and inflammatory markers for cardiovascular disease, Eur Heart J 26 (2005), 1765-1773.

[14] L.A. Bazzano, J. He, P. Muntner, S. Vupputuri and P.K. Whelton, Relationship between cigarette smoking and novel risk factors for cardiovascular disease in the United States, Ann Intern Med 138 (2003), 891-897.

[15] S. Mora, I.M. Lee, J.E. Buring and P.M. Ridker, Association of physical activity and body mass index with novel and traditional cardiovascular biomarkers in women, JAMA 295 (2006), 1412-1419.

[16] S.G. Wannamethee, G.D. Lowe, P.H. Whincup, A. Rumley, M. Walker and L. Lennon, Physical activity and hemostatic and inflammatory variables in elderly men, Circulation $\mathbf{1 0 5}$ (2002), 1785-1790.

[17] J.L. Abramson and V. Vaccarino, Relationship between physical activity and inflammation among apparently healthy middle-aged and older US adults, Arch Intern Med 162 (2002), 1286-1292.

[18] D. Verdaet, P. Dendale, D. De Bacquer, J. Delanghe, P. Block and G. De Backer, Association between leisure time physical activity and markers of chronic inflammation related to coronary heart disease, Atherosclerosis 176 (2004), 303-310.

[19] E.S. Rawson, P.S. Freedson, S.K. Osganian, C.E. Matthews, G. Reed and I.S. Ockene, Body mass index, but not physical activity, is associated with C-reactive protein, Med Sci Sports Exerc 35 (2003), 1160-1166.

[20] A. Esmaillzadeh, M. Kimiagar, Y. Mehrabi, L. Azadbakht, F.B. Hu and W.C. Willett, Fruit and vegetable intakes, Creactive protein, and the metabolic syndrome, Am J Clin Nutr 84 (2006), 1489-1497.

[21] M.A. Albert, R.J. Glynn and P.M. Ridker, Alcohol consumption and plasma concentration of C-reactive protein, Circulation 107 (2003), 443-447.

[22] M. Visser, L.M. Bouter, G.M. McQuillan, M.H. Wener and T.B. Harris, Elevated C-reactive protein levels in overweight and obese adults, JAMA 282 (1999), 2131-2135.

[23] C.L. Ogden, M.D. Carroll, L.R. Curtin, M.A. McDowell, C.J. Tabak and K.M. Flegal, Prevalence of overweight and obesity in the United States, 1999-2004, JAMA 295 (2006), 15491555 .

[24] A.H. Berg and P.E. Scherer, Adipose tissue, inflammation, and cardiovascular disease, Circ Res 96 (2005), 939-949.
[25] V. Mohamed-Ali, S. Goodrick, A. Rawesh, D.R. Katz, J.M. Miles, J.S. Yudkin, S. Klein and S.W. Coppack, Subcutaneous adipose tissue releases interleukin-6, but not tumor necrosis factor-alpha, in vivo, J Clin Endocrinol Metab 82 (1997), 4196-4200.

[26] A.S. Shamsuzzaman, M. Winnicki, R. Wolk, A. Svatikova, B.G. Phillips, D.E. Davison, P.B. Berger and V.K. Somers, Independent association between plasma leptin and C-reactive protein in healthy humans, Circulation 109 (2004), 21812185.

[27] S.M. Abdullah, A. Khera, D. Leonard, S.R. Das, R.M. Canham, S.A. Kamath, G.L. Vega, S.M. Grundy, D.K. McGuire and J.A. de Lemos, Sex differences in the association between leptin and CRP: Results from the Dallas Heart Study, Atherosclerosis (2006), [Epub ahead of print].

[28] N. Ouchi, S. Kihara, T. Funahashi, T. Nakamura, M. Nishida, M. Kumada, Y. Okamoto, K. Ohashi, H. Nagaretani, K. Kishida, H. Nishizawa, N. Maeda, H. Kobayashi, H. Hiraoka and Y. Matsuzawa, Reciprocal association of C-reactive protein with adiponectin in blood stream and adipose tissue, Circulation 107 (2003), 671-674.

[29] M.B. Snijder, R.M. van Dam, M. Visser and J.C. Seidell, What aspects of body fat are particularly hazardous and how do we measure them? Int J Epidemiol 35 (2006), 83-92.

[30] D. Gallagher, M. Visser, D. Sepulveda, R.N. Pierson, T. Harris and S.B. Heymsfield, How useful is body mass index for comparison of body fatness across age, sex, and ethnic groups? Am J Epidemiol 143 (1996), 228-239.

[31] D. Gallagher, P. Kuznia, S. Heshka, J. Albu, S.B. Heymsfield, B. Goodpaster, M. Visser and T.B. Harris, Adipose tissue in muscle: a novel depot similar in size to visceral adipose tissue, Am J Clin Nutr 81 (2005), 903-910.

[32] C.E. Ruhl, J.E. Everhart, J. Ding, B.H. Goodpaster, A.M. Kanaya, E.M. Simonsick, F.A. Tylavsky and T.B. Harris, Health, Aging, and Body Composition Study. Serum leptin concentrations and body adipose measures in older black and white adults, Am J Clin Nutr 80 (2004), 576-583.

[33] J.C. Winer, T.L. Zern, S.E. Taksali, J. Dziura, A.M. Cali, M. Wollschlager, A.A. Seyal, R. Weiss, T.S. Burgert and S. Caprio, Adiponectin in childhood and adolescent obesity and its association with inflammatory markers and components of the metabolic syndrome, J Clin Endocrinol Metab 91 (2006), $4415-4423$. 


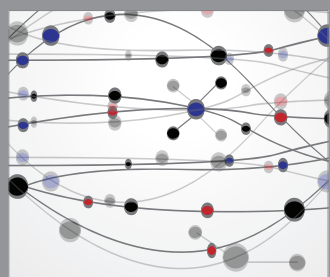

The Scientific World Journal
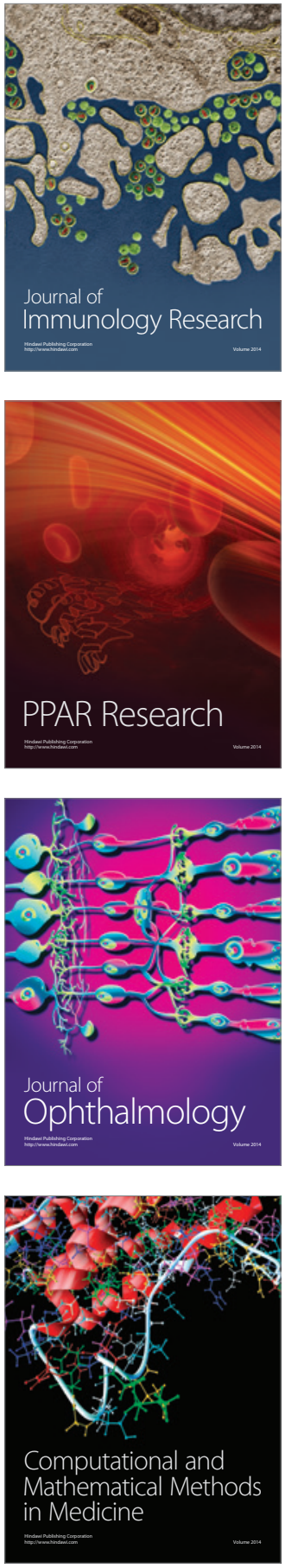

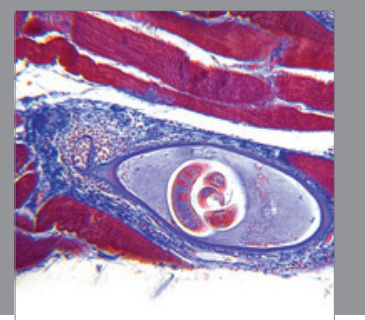

Gastroenterology

Research and Practice
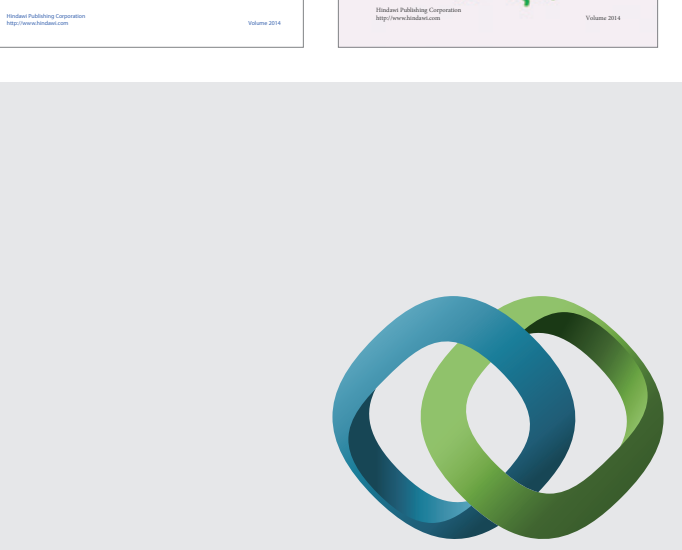

\section{Hindawi}

Submit your manuscripts at

http://www.hindawi.com
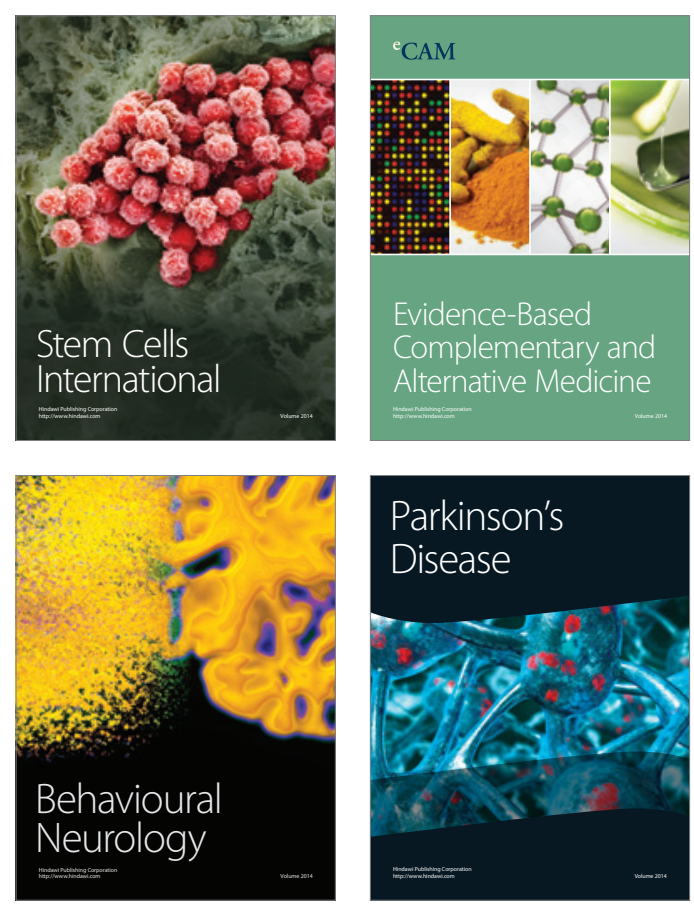

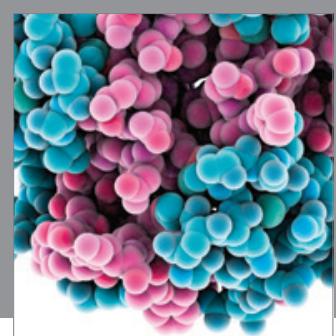

Journal of
Diabetes Research

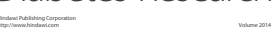

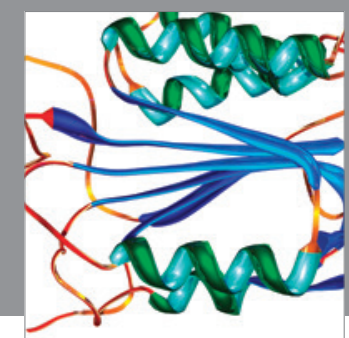

Disease Markers
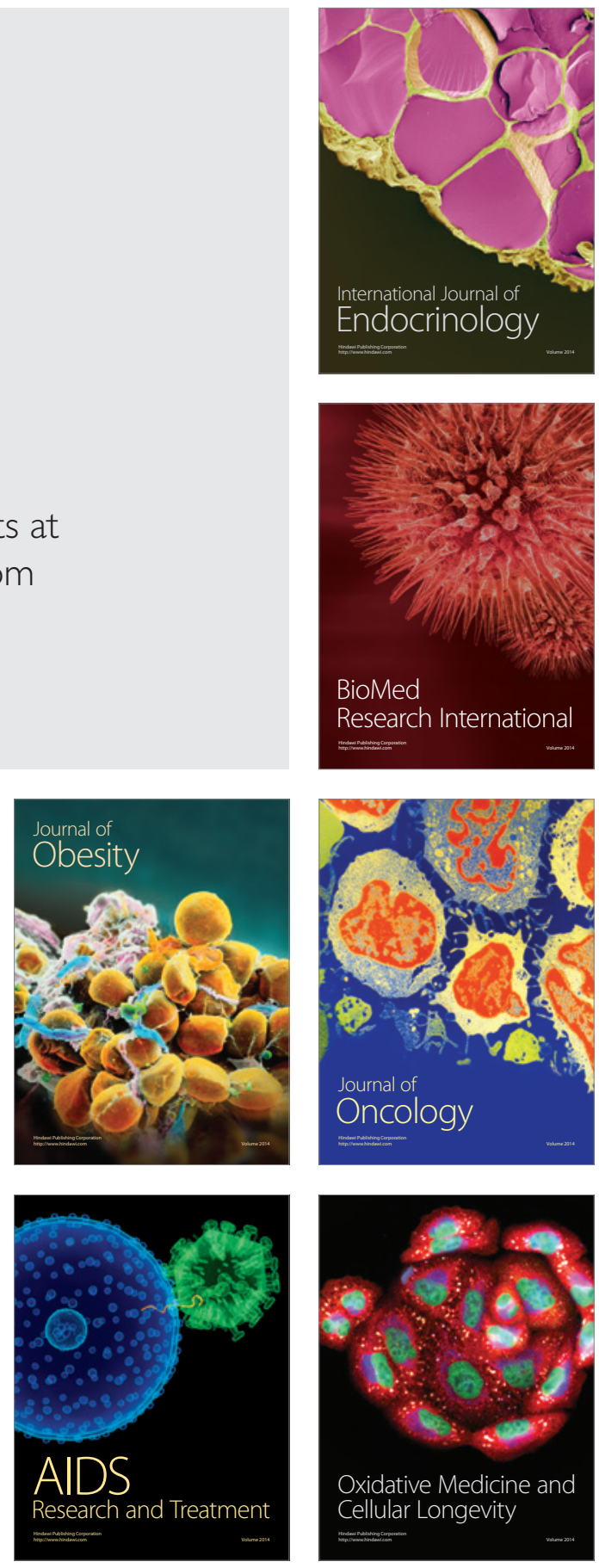